\title{
O CURSO DE PEDAGOGIA EM FOCO: A INSERÇÃO DOS EGRESSOS DA UNIVERSIDADE FEDERAL DE OURO PRETO NO CAMPO PROFISSIONAL
}

\section{The pedagogy course in focus: the insertion of graduates from the Universidade Federal de Ouro Preto in the professional field}

El curso de pedagogía en foco: la inserción de los graduados del Universidade Federal de Ouro Preto en el ámbito profesional

Celia Maria Fernandes Nunes* Regina Magna Bonifácio de Araújo**

Nilzilene Imaculada Lucindo***

Íris Madalena Feijó Braga****

\section{Resumo}

Este artigo tem como objetivo apresentar as contribuições de estudo desenvolvido com alunos(as) egressos(as) do curso de Pedagogia de uma IES pública federal, localizada na Região Sudeste brasileira. Duas pesquisas foram realizadas com os egressos do curso de Pedagogia em momentos distintos 2016 e 2019. Ambas utilizaram na coleta de dados um questionário na Plataforma Google Forms, estruturado em quatro eixos de análise: o perfil; a formação acadêmica; a atuação profissional; o curso de Pedagogia e a profissão de pedagogo, encaminhado via e-mail. A análise dos dados foi realizada com base nas respostas dos egressos, utilizando-se para as questões abertas a técnica de análise de conteúdo. Os dados obtidos caracterizaram o perfil dos egressos e propiciou uma análise da inserção e atuação desses graduandos no campo profissional.

Palavras-chave: Curso de Pedagogia; Egressos, Campo Profissional. 
Celia Maria Fernandes Nunes, Regina Magna Bonifácio de Araújo, Nilzilene Imaculada Lucindo e Íris Madalena Feijó Braga

\begin{abstract}
This article aims to present the contributions of a study developed with students graduating from the Pedagogy course of a higher education institution, located in the southeast region of Brazil. Two surveys were conducted with graduates of the Pedagogy course at different times in 2016 and 2019. Both used a questionnaire on the Google Forms Platform to collect data, structured in four axes of analysis: the profile; academic training; professional performance; the Pedagogy course and the teaching profession, sent via e-mail. Data analysis was performed based on the responses of the graduates, using the content analysis technique for open questions. The data obtained characterized the profile of the graduates and provided an analysis of the insertion and performance of these graduates in the professional field.
\end{abstract}

Keywords: Pedagogy Course; Graduates, Professional Field.

\title{
Resumen
}

Este artículo tiene como objetivo presentar las contribuciones de un estudio desarrollado con estudiantes egresados del curso de Pedagogía de una IES pública federal, ubicada en la región Sudeste de Brasil. Se realizaron dos encuestas a egresados del curso de Pedagogía en diferentes momentos durante 2016 y 2019. Ambos utilizaron un cuestionario en la Plataforma Google Forms, para la recolección de datos, estructurado en cuatro ejes de análisis: el perfil; entrenamiento académico; rendimiento profesional; el curso de Pedagogía y Profesión Docente, enviado vía e-mail. El análisis de datos se realizó en base a las respuestas de los egresados, utilizando la técnica de análisis de contenido para preguntas abiertas. Los datos obtenidos caracterizaron el perfil de los egresados y proporcionaron un análisis de la inserción y desempeño de estos egresados en el ámbito profesional.

Palabras clave: Curso de Pedagogía; Graduados; Campo Profesional.

\section{Introdução}

Ao longo dos anos, o curso de Pedagogia passou por várias reformas curriculares e discussões no bojo acadêmico e das políticas públicas educacionais. Não obstante, vale destacar a resolução do Conselho Nacional de Educação - $\mathrm{CNE} \mathrm{n}^{\circ} 1$, de 15 de maio de 2006, que instituiu as Diretrizes Curriculares Nacionais para os cursos de graduação em Pedagogia-Licenciatura, iniciando uma nova fase para o curso no que diz respeito à formação do pedagogo(a). 
Segundo as Diretrizes Curriculares Nacionais do curso de Pedagogia-Licenciatura este é destinado à formação inicial para o exercício da docência na Educação Infantil e para os anos iniciais do Ensino Fundamental, assim como para atuar nos cursos de Educação Profissional, na área de serviços e apoio escolar. Prevê ainda a formação para atuar em outras áreas nas quais sejam previstos conhecimentos pedagógicos (BRASIL, 2006) $)^{1}$.

Questionamentos acerca da formação desse profissional deram origem a várias pesquisas, que dentre outras temáticas, discutem as disciplinas que devem compor o currículo para este curso. No estudo realizado por Gatti e Barreto (2009) sobre o projeto pedagógico de 71 cursos de licenciatura, as autoras constataram uma variedade de disciplinas no curso de Pedagogia, que contemplam os três núcleos das Diretrizes: 1) estudos básicos; 2) aprofundamento e diversificação de estudos; 3 ) estudos integradores. Segundo Pimenta et al. (2017) e Gatti e Barreto (2009), o quadro de disciplinas do curso de Pedagogia dispõe de muitas disciplinas teóricas, poucas referências voltadas para práticas de ensino e para temáticas que contribuam para compreender como atuar no contexto educacional brasileiro. Gatti e Barreto (2009, p.121) ainda enfatizam ao analisar os subgrupos curriculares, que

Entre as disciplinas que compõem a categoria fundamentos teóricos da educação ( $26 \%$ do total), apenas $3,4 \%$ se referem a didática geral. $\mathrm{O}$ grupo das didáticas específicas, metodologias e práticas de ensino (o "como" ensinar) representa $20,7 \%$ do total, e as disciplinas voltadas aos conteúdos a serem ensinados nas séries iniciais do ensino fundamental constituem apenas 7,5\% do conjunto. Por essas indicações torna-se evidente que os conteúdos específicos das disciplinas a serem ministradas em sala de aula nas escolas não são objeto dos cursos de formação inicial docente.

Também não são objeto de estudo aprofundado as temáticas sobre Educação Infantil, Educação de Jovens e Adultos ou Educação Especial, ou mesmo dos conhecimentos referentes ao magistério das séries iniciais do Ensino Fundamental, conforme pesquisa desenvolvida por Albuquerque, Haas e Araújo (2013). Tal cenário retratado pelas matrizes curriculares de formação para a docência nos permite questionar: quais são as demandas e os desafios da formação de professores para atender ao atual

\footnotetext{
${ }^{1}$ Há de se destacar Resoluções mais recentes que afetam diretamente o Curso de Pedagogia quais sejam: RESOLUÇÃO No 2, DE $1^{\circ}$ DE JULHO DE 2015 - Define as Diretrizes Curriculares Nacionais para a formação inicial em nível superior (cursos de licenciatura, cursos de formação pedagógica para graduados e cursos de segunda licenciatura) e para a formação continuada e RESOLUÇÃO CNE/CP N ${ }^{\circ}$ 2, DE 20 DE DEZEMBRO DE 2019 - Define as Diretrizes Curriculares Nacionais para a Formação Inicial de Professores para a Educação Básica e institui a Base Nacional Comum para a Formação Inicial de Professores da Educação Básica (BNC-Formação).
} 
mercado de trabalho, a realidade e os problemas enfrentados pelas redes de ensino do país? E o que é necessário ser alterado no processo de formação desse profissional?

Não obstante, diante do cenário de formação docente exposto pelas recentes pesquisas, é fundamental para alcançar a qualidade de ensino, sobretudo na rede de ensino público brasileiro, que as instituições que ofertam os cursos de licenciatura em Pedagogia, bem como as autoridades responsáveis por políticas e financiamento da educação superior, busquem refletir e propor mudanças na matriz curricular dos cursos, de forma que atendam às demandas atuais das escolas que vivenciam um processo lento de inclusão da diversidade, além de dispor de um grupo de estudantes plural, que a cada dia exige do docente conhecimentos sociais, culturais, que ainda não estão incorporados ao processo formativo, tampouco associados às disciplinas de metodologia de ensino, tão importantes para a prática docente e para o processo de aprendizagem dos discentes.

Neste enfoque, desde 2010 temos desenvolvido pesquisas ${ }^{2}$ que abordam a formação e o lugar profissional do pedagogo, buscando problematizar e discutir acerca do profissional pedagogo, sua formação inicial, o impacto das Diretrizes Curriculares para o curso e a inserção dos egressos no mercado de trabalho. Dentre as duas pesquisas desenvolvidas destacamos o conteúdo desse artigo que tem como objetivo trazer à discussão elementos para pensar sobre o curso de Pedagogia a partir da análise do campo de atuação profissional dos seus egressos.

Definimos como egressos de Pedagogia, aqueles ex-alunos que cumpriram a matriz curricular do curso obtendo assim a titulação na área Ferreira (2004). Assim as pesquisas referentes às trajetórias dos egressos, da formação inicial ao mercado de trabalho, tornaram-se elementar enquanto uma possibilidade de avaliar as instituições, tomando como variáveis de análise: o perfil dos egressos, efetividade profissional, avaliação do curso e relação com a instituição, entre outros possíveis fatores de análise.

De acordo com Paul (2015) as primeiras pesquisas sobre egressos surgem entre os anos de 1960 a 1980, diante de um cenário educacional de ampliação de matrículas no ensino superior em todo o mundo, no qual se observa que:

Na Europa, em especial na França, eles triplicaram entre 1970 e 2010. Na América Latina, os números de matrículas foram multiplicados por onze e no Brasil por quinze. Na França, em uma geração, $42 \%$ dos

\footnotetext{
${ }^{2}$ Iniciamos com uma parceria entre a PUC-SP e a Universidade Municipal de São Caetano do Sul. Ao todo foram 4 (quatro) pesquisas, todas inscritas e aprovadas nos Editais da Universidade e agências de pesquisa (PROBIC/Fapemig; PIBIC/CNPQ), com bolsistas remuneradas. A temática de pesquisas com egressos da Pedagogia foram abordadas por meio de duas pesquisas sendo uma realizada em 2016 e outra em 2019.
} 
jovens estão saindo do sistema educativo com um diploma do ensino superior, contra 15\% em 1985 e 32\% em 1995 (PAUL, 2015, p.310).

No escopo temático desse artigo, abordamos a inserção dos alunos e alunas egressos do curso de Pedagogia no campo profissional. Nesse propósito, na constituição de um caminho metodológico mais adequado a responder as questões propostas recorremos a uma abordagem qualitativa e quantitativa, através de pesquisa bibliográfica e documental, por considerar algumas especificidades dos participantes, como local de residência e forma de contato.

Realizamos, inicialmente, uma pesquisa de campo buscando informações da relação de egressos no setor responsável pelo sistema de registro acadêmico da instituição. Nos dados pudemos identificar os nomes e endereços de contatos dos egressos que haviam colado grau desde sua criação. Após a localização desses egressos do curso de Pedagogia e sujeitos da pesquisa encaminhamos e encaminhamos um questionário através da plataforma Google Forms, contendo 52 questões, abertas e fechadas, subdividido em quatro seções: 1) Identificação; 2) Formação Acadêmica; 3) Atuação Profissional; 4) O curso de Pedagogia e a profissão de Pedagogo. Tais seções nos permitiram realizar uma análise do perfil dos egressos da Pedagogia, sua formação acadêmica e sua inserção no mercado de trabalho. Contabilizou-se como possíveis colaboradores da pesquisa 287 egressos e responderam ao inquérito 124 egressos.

Os dados foram tabulados, estruturados, tratados e analisados por meio das ferramentas do Excel® e do software de análise estatística Minitab®. O tratamento dos dados consistiu na eliminação de informações duplicadas; adequação e classificação de respostas que não pertenciam a determinada questão como N/R (não respondido), N/A (não se aplica) ou inconclusivas; adequação do preenchimento de datas que deveriam ser respondidas no formato completo para o formato simples de ano, pois não era possível identificar a data completa da maioria das respostas obtidas; adequação das respostas abertas em "sim" e "não" a fim de melhor representá-las graficamente; agrupamento e classificação das respostas abertas por assuntos do mesmo gênero para posterior análise. A seguir considerando os objetivos da pesquisa apresentamos os dados analisados.

\section{O campo de atuação dos egressos do curso de Pedagogia}

Os dados evidenciados nesta seção explicitam os resultados das duas pesquisas realizadas com os egressos do curso de Pedagogia. Na apresentação desses, optou-se por 
agrupar os achados da investigação em dois subitens. Inicialmente, serão abordados os dados da primeira pesquisa "Por onde andam os ex-alunos do curso de Pedagogia/UFOP? Conhecendo a trajetória e o lugar profissional desses egressos", realizada entre os anos de 2016 e 2018 e, na sequência, os dados da segunda investigação, intitulada: "O aluno egresso do curso de Pedagogia da Universidade Federal de Ouro Preto: trajetória e inserção profissional", iniciada em 2019 e concluída em 2020.

Dessa forma, a partir do recorte estabelecido vislumbra-se discutir o campo de atuação desses egressos enfocando: o perfil do egresso, as áreas de atuação, o tipo de organização em que trabalham, as formas de obtenção do emprego, o tempo entre a formação e a obtenção do emprego, o período de ingresso no mercado de trabalho, o nível de satisfação com a profissão nos aspectos financeiro e social. Ao fazê-lo será possível estabelecer uma comparação entre os resultados alcançados com as duas investigações realizadas e identificar semelhanças e divergências em relação ao campo de atuação dos egressos do curso de Pedagogia.

Da primeira investigação cujo público-alvo se constituiu de 145 egressos que se formaram entre os anos de 2012 e 2015 participaram 70 licenciados, o que corresponde a uma amostra de 48,2\% dos egressos. Para 58,6\% deles, no processo seletivo, o curso de Pedagogia foi sua primeira opção e $41,4 \%$ escolheram outro curso.

Ao caracterizar o perfil desses participantes, detectou-se que 94,3\% são mulheres e 5,7\% são homens. A grande maioria ingressou no curso e o concluiu quando estavam na faixa etária de 20 a 30 anos. A maior parte dos egressos se declarou pardo $(37,1 \%)$ e branco $(32,9 \%)$, contudo, 22,8\% dos estudantes se declararam negro. Em relação ao estado civil, 55,7\%, se declararam solteiros, 34,3\% casados; 4,3\% divorciados; 4,3\% com união estável e 1,4\% assinalaram a opção "outros”. Metade dos egressos é natural da região onde a instituição de ensino superior (IES) pesquisada está inserida, com destaque para as cidades de Diogo de Vasconcelos, Itabirito, Mariana e Ouro Preto, em Minas Gerais; 28,7\% são nascidos em outros municípios do interior mineiro; 7,1\% são naturais de Belo Horizonte, capital do Estado e 7,1\% são naturais de outros estados do Brasil. Deixou de responder a essa questão o percentual de 7,1\%. Dentre os participantes da pesquisa, 82,9\% concluíram o Ensino Fundamental em instituição de ensino pública, 78,6\% concluíram o Ensino Médio também em instituições de ensino públicas e 54,3\% afirmaram que cursaram ou estão cursando uma Pós-Graduação.

No que tange ao ingresso dos investigados no mercado de trabalho, constatou-se que $75,7 \%$ deles estão trabalhando; $21,4 \%$ não trabalham e 2,9\% não responderam a essa 
questão. As áreas de atuação em que os egressos estão trabalhando seguem representadas na Tabela 01.

Tabela 01- Áreas de atuação dos egressos

\begin{tabular}{lc}
\hline Áreas de Atuação & Quantitativo \\
\hline Educacional & $72,9 \%$ \\
Empresarial & $0 \%$ \\
Industrial & $0 \%$ \\
Comercial & $0 \%$ \\
Outras & $4,3 \%$ \\
Não Responderam & $22,8 \% \%$ \\
\hline Total & $100,0 \%$ \\
\hline
\end{tabular}

Quanto ao tipo de organização na qual os egressos exercem sua atividade profissional, verificou-se que 51,4\% trabalham em instituição pública e $22,9 \%$ em instituição privada. Os demais não responderam ou a questão não se aplicava a sua situação atual.

A forma de obtenção do emprego é explicitada no Gráfico 01.

Gráfico 01- Formas de obtenção do emprego

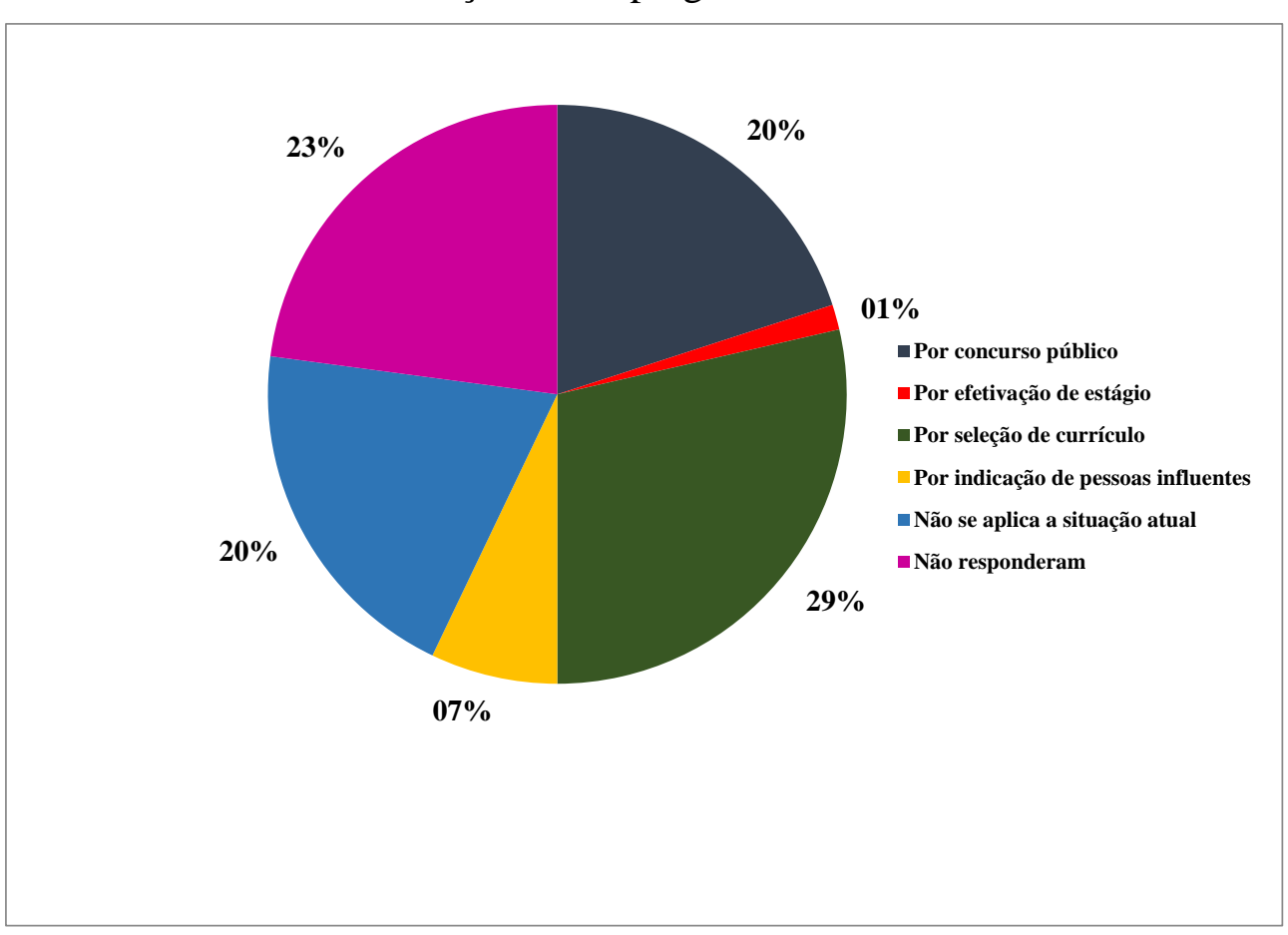

Fonte: Elaboração própria a partir de questionário aplicado no ano de 2016 
A obtenção do emprego por meio de currículo demonstra, além da escassez de concursos públicos nos últimos anos, que há uma maior valorização das experiências e da formação adquiridas. Neste caso, consideram-se essenciais as experiências formadoras oferecidas durante a graduação e que favorecem o desenvolvimento profissional dos licenciandos, como por exemplo as atividades extracurriculares, a participação dos acadêmicos em projetos de extensão, de iniciação científica e outras tantas como por exemplo, no Programa de Educação Tutorial (PET PEDAGOGIA), Programa Institucional de Bolsas de Iniciação à Docência (PIBID), além dos estágios.

No que concerne ao período/época de ingresso no mercado, 41,4\% dos egressos ingressaram no mercado enquanto ainda estavam cursando Pedagogia; 18,6\% imediatamente após a conclusão do curso; $17,1 \%$ até seis meses após a conclusão do curso; 8,6\% ainda não ingressaram no mercado de trabalho; 5,7\% mais de um ano após a conclusão do curso; 4,3\% depois de seis meses a um ano, sendo que 4,3\% não responderam a essa questão.

Ao analisar o tempo decorrido entre a formatura e o início da atividade profissional, averiguou-se que $67,2 \%$ dos egressos que estão trabalhando ingressaram no mercado de trabalho com menos de um ano; 5,7\% dos egressos levaram de 2 a 3 anos e 1,4\% levaram de 1 a 4 anos, fato que revela a importância da formação desses profissionais para o atendimento da demanda onde está inserida a universidade, já que é a única instituição pública que oferece o curso de Pedagogia na região.

Ao serem questionados acerca de sua satisfação com a profissão de Pedagogo, $70 \%$ responderam que estão satisfeitos com a profissão, como pode ser observado nos relatos de $\mathrm{P}^{3} 5^{3}$ e $\mathrm{P} 57$, respectivamente.

Sim, pois me sinto realizada quando entro em uma sala de aula e vejo meus alunos aprendendo (P45);

Sim. Apesar de tantos desafios que encontramos, nossa profissão é a base para o progresso do mundo (P57);

Segundo $11,4 \%$, estão satisfeitos em parte e 4,3\% não estão satisfeitos com a profissão. Dentre aqueles que "estão satisfeitos em parte" destaca-se o relato de P65:

Em partes. É satisfatório ver que contribuímos para o crescimento de um sujeito, mas é muito triste e deplorável a situação de um Educador nos dias atuais. Muito se fala em valorização, mas pouco se vê. $E$ todos

\footnotetext{
${ }^{3}$ Atendendo aos preceitos da ética na pesquisa com seres humanos, os egressos foram identificados por um $\mathrm{P}$, de Pedagogo, com vistas a preservar sua identidade.
} 
reconhecem ser a profissão base, aquela que norteia a vida educacional de um sujeito, mas reconhecer e não agir não basta (P65);

E dentre os insatisfeitos, ressalta-se o relato de P16, o qual afirma que "Não. A remuneração não é o que eu esperava" e de P35, o qual esclarece que "Não. Quero ingressar na área de exatas, que eu descobri que é o que eu gosto e quero fazer". Deixaram de responder a essa questão $10 \%$ dos participantes e $4,3 \%$ informaram que ainda não estão atuando.

Os Gráficos 02 e 03, a seguir, ilustram o nível de satisfação dos egressos com a situação profissional nos aspectos financeiro e social.

Gráfico 02- Nível de satisfação com a situação profissional - aspecto financeiro

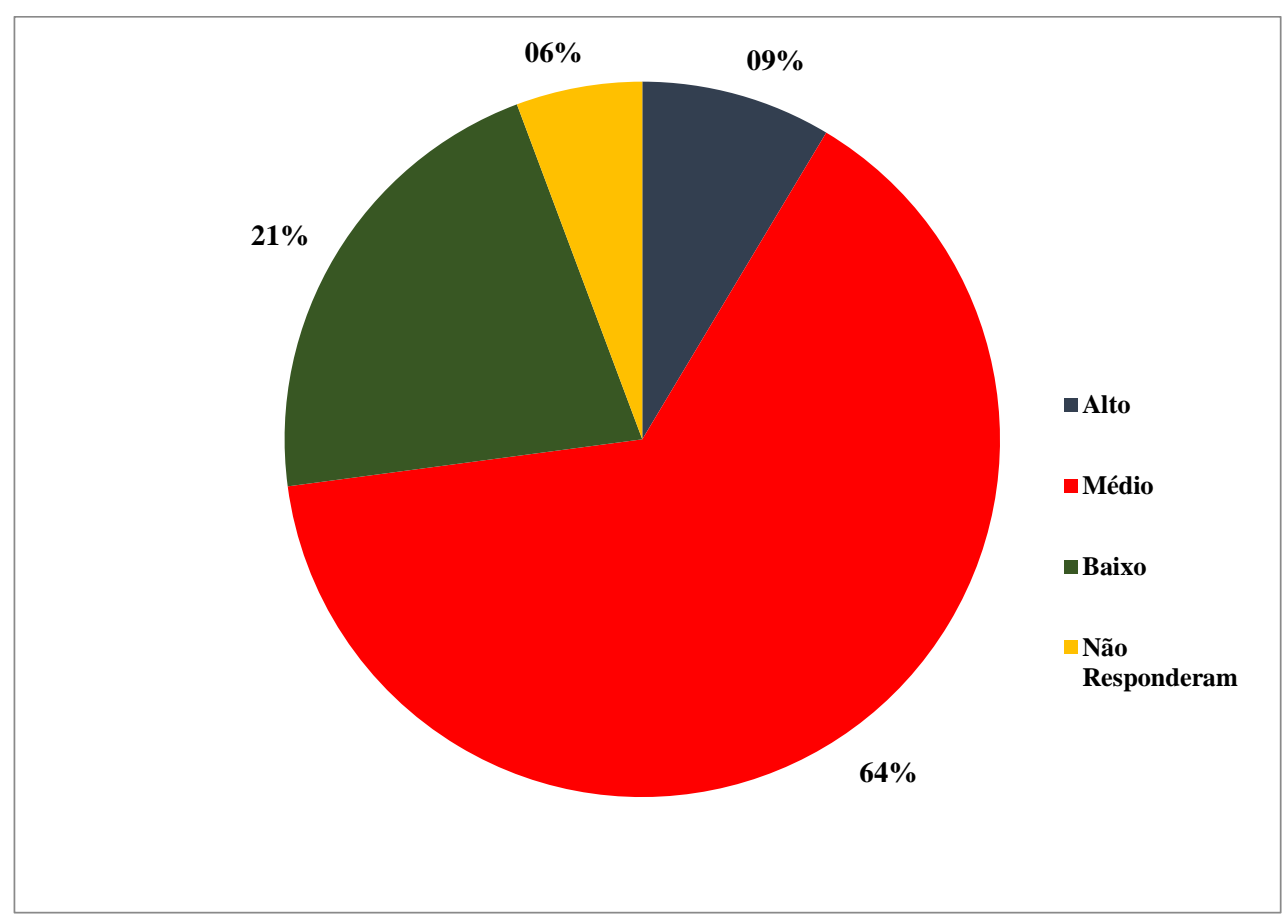

Fonte: Elaboração própria a partir de questionário aplicado no ano de 2016 
Gráfico 03- Nível de satisfação com a situação profissional - aspecto social

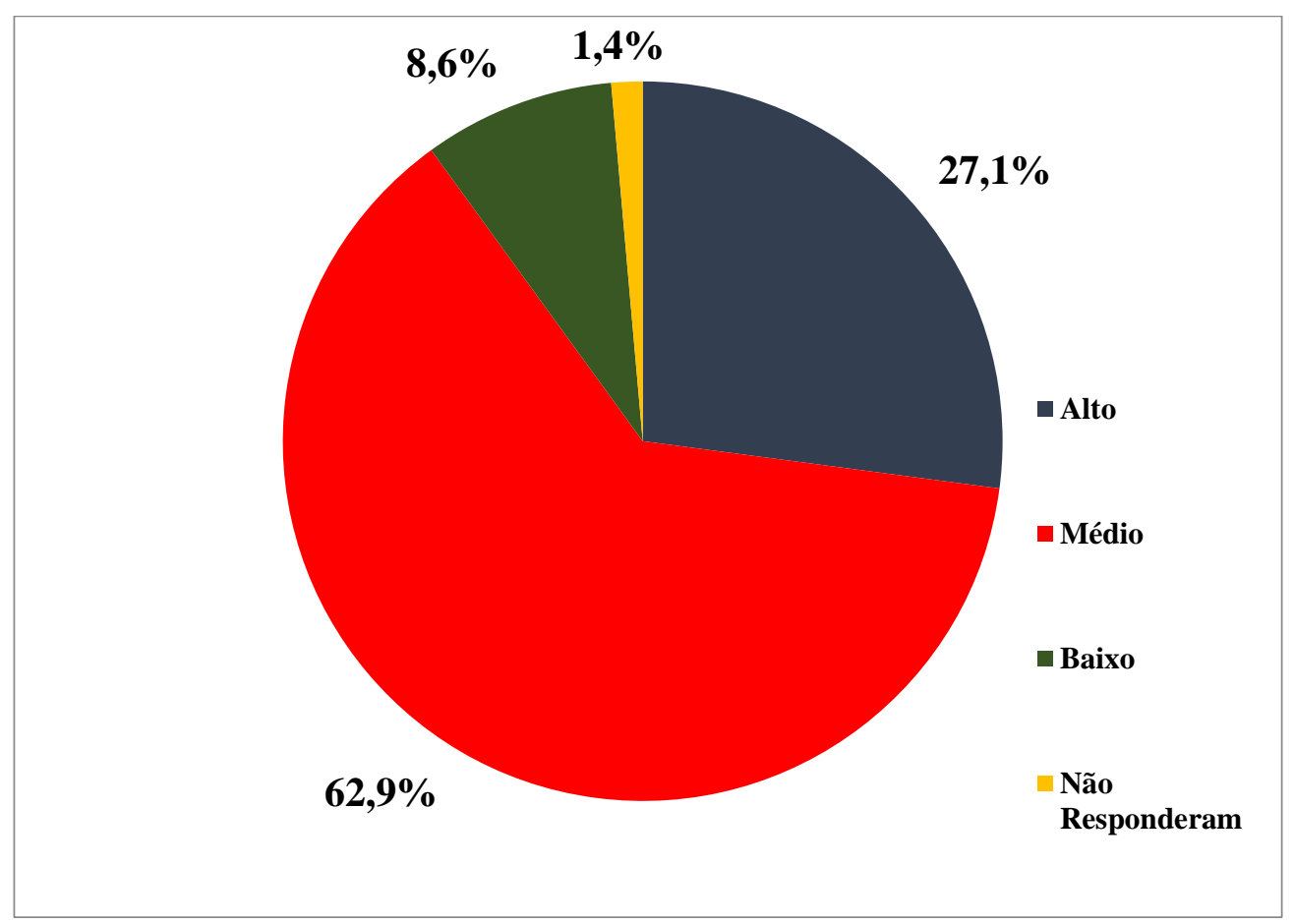

Fonte: Elaboração própria a partir de questionário aplicado no ano de 2016

A análise de ambos os gráficos demonstra que os percentuais de satisfação com situação profissional se aproximam, tanto no aspecto social quanto no aspecto financeiro, uma vez que a maior parte dos participantes registram um nível médio de satisfação.

$\mathrm{Na}$ segunda investigação, o público-alvo se constituiu de 142 egressos que se formaram entre os anos de 2016 e 2019. Participaram dessa pesquisa 54 licenciados, o que corresponde a uma amostra de $38 \%$ dos egressos. Segundo $57,4 \%$ dos respondentes, no processo seletivo, o curso de Pedagogia foi sua primeira opção, enquanto $42,5 \%$ possuíam outro curso como primeira opção.

Ao traçar o perfil dos participantes dessa investigação, constatou-se que 94,4\% são mulheres e 5,6\% são homens. A faixa etária da maior parte dos egressos, 75\%, está concentrada entre 19 e 30 anos. Em relação a cor/raça, a maior parte, 42,6\% se declarou branca, 33,3\% se declararam pardos; $22,2 \%$ negro e 1,9\% amarelo. Quanto ao estado civil, $57,4 \%$ se declararam solteiros, em contrapartida $27,7 \%$ são casados, $7,4 \%$ vivem em união estável e 7,4\% são divorciados. No que diz respeito a naturalidade dos egressos averiguou-se que 88,9\% são mineiros, 5,6\% são naturais do estado do Rio de Janeiro, $3,7 \%$ de São Paulo e 1,8\% de Goiás. Os egressos, são oriundos, em sua maioria, da escola pública, sendo que $83,3 \%$ concluíram o Ensino Fundamental e 55,9\% concluíram o 
Ensino Médio em instituições de ensino públicas. Dentre os participantes da pesquisa, 14,8\% afirmaram que cursaram ou estão cursando uma Pós-Graduação.

Sobre a inserção dos egressos no mercado de trabalho, apurou-se que $74 \%$ deles estavam trabalhando e $26 \%$ não trabalhavam. As áreas em que esses egressos trabalham podem ser visualizadas na Tabela 02 .

Tabela 02- Áreas de atuação dos egressos

\begin{tabular}{lc}
\hline Áreas de Atuação & Quantitativo \\
\hline Educacional & $87,5 \%$ \\
Empresarial & $2,5 \%$ \\
Industrial & $0 \%$ \\
Comercial & $2,5 \%$ \\
Outras & $7,5 \%$ \\
\hline Total & $100,0 \%$ \\
\hline
\end{tabular}

Fonte: Elaboração própria a partir de questionário aplicado no ano de 2019.

No que tange aos tipos de organização da área educacional como atividade profissional, dos $87,5 \%$ egressos que exerciam sua profissão no campo da educação, $63 \%$ trabalhavam em instituição pública, $31 \%$ em instituição privada e $6 \%$ responderam que a pergunta não se aplicava a situação atual.

A forma como os egressos obtiveram o emprego é evidenciada no Gráfico 04.

Gráfico 04- Formas de obtenção do emprego

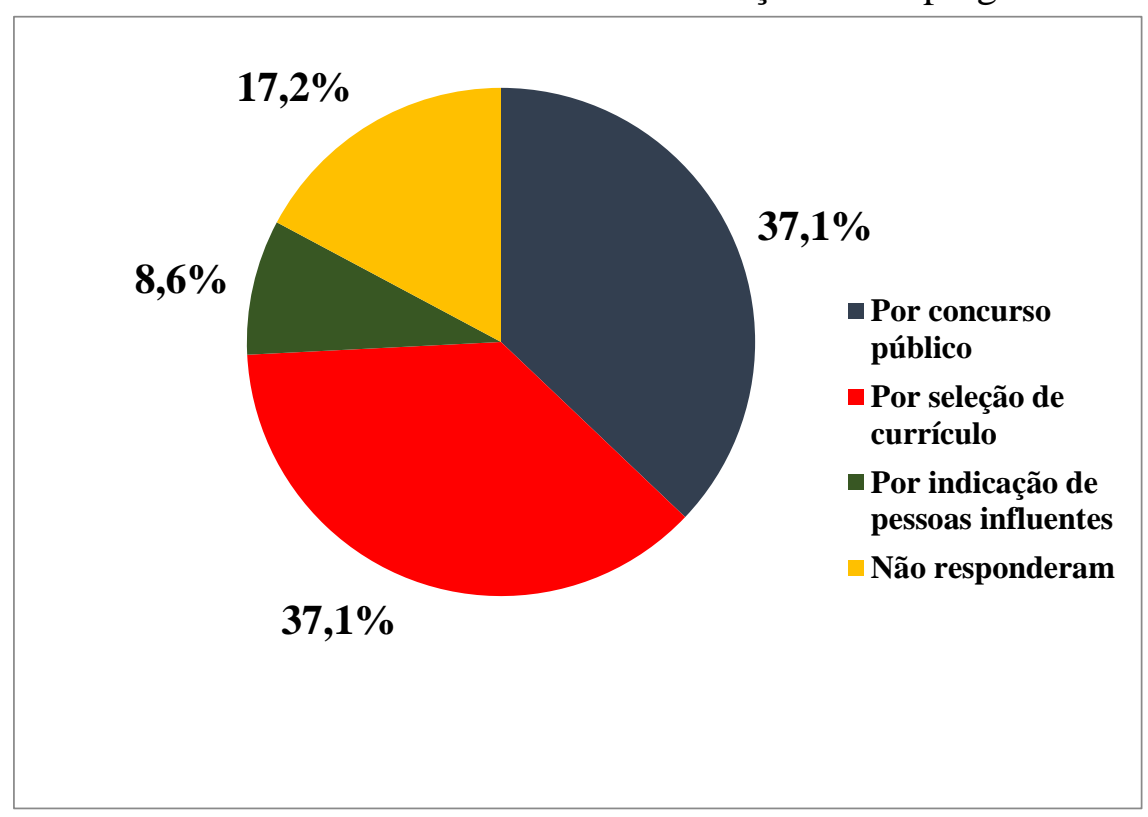

Fonte: Elaboração própria a partir de questionário aplicado no ano de 2019. 
Ao apurar o tempo decorrido entre a formatura e o início da atividade profissional, verificou-se que $22,2 \%$ dos egressos ingressaram no mercado de trabalho imediatamente após a conclusão do curso; 22,2\% enquanto ainda estavam cursando Pedagogia; $18,5 \%$ até seis meses após a conclusão do curso; sendo que 18,5\% ainda não ingressaram no mercado de trabalho e $11,1 \%$ começaram a trabalhar no período entre seis meses a um ano após a conclusão do curso. Apenas 7,5\% começaram com mais de um ano após a conclusão do curso.

Acerca da satisfação com a profissão de Pedagogo, foram avaliados os níveis de satisfação dos egressos com a situação profissional nos aspectos financeiro e social. Do total de participantes da pesquisa, responderam a essa questão 64,8\% dos egressos. Os resultados seguem demonstrados nos Gráficos 05 e 06, a seguir.

Gráfico 05- Nível de satisfação com a situação profissional - aspecto financeiro

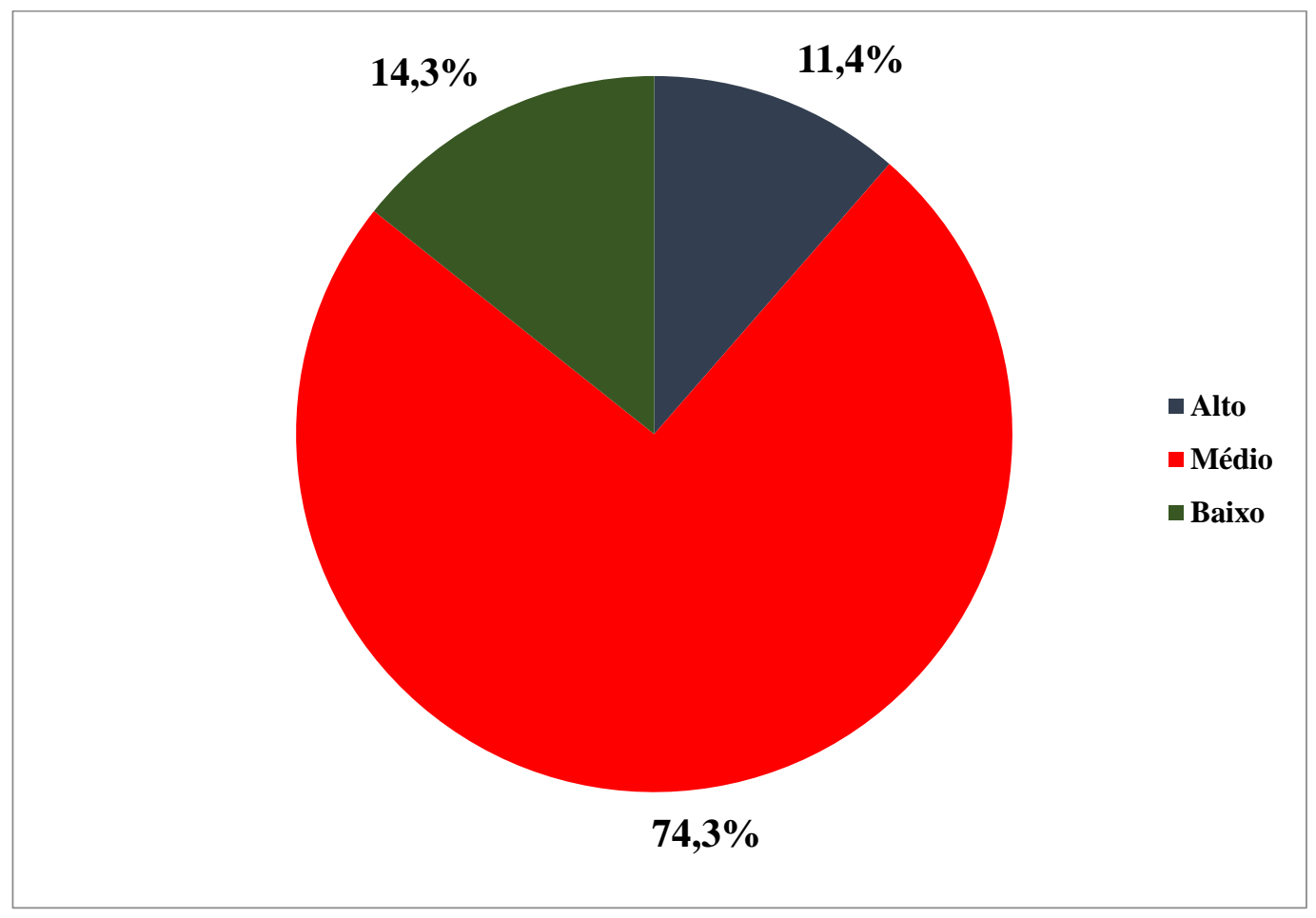

Fonte: Elaboração própria a partir de questionário aplicado no ano de 2019. 
Gráfico 06- Nível de satisfação com a situação profissional - aspecto social

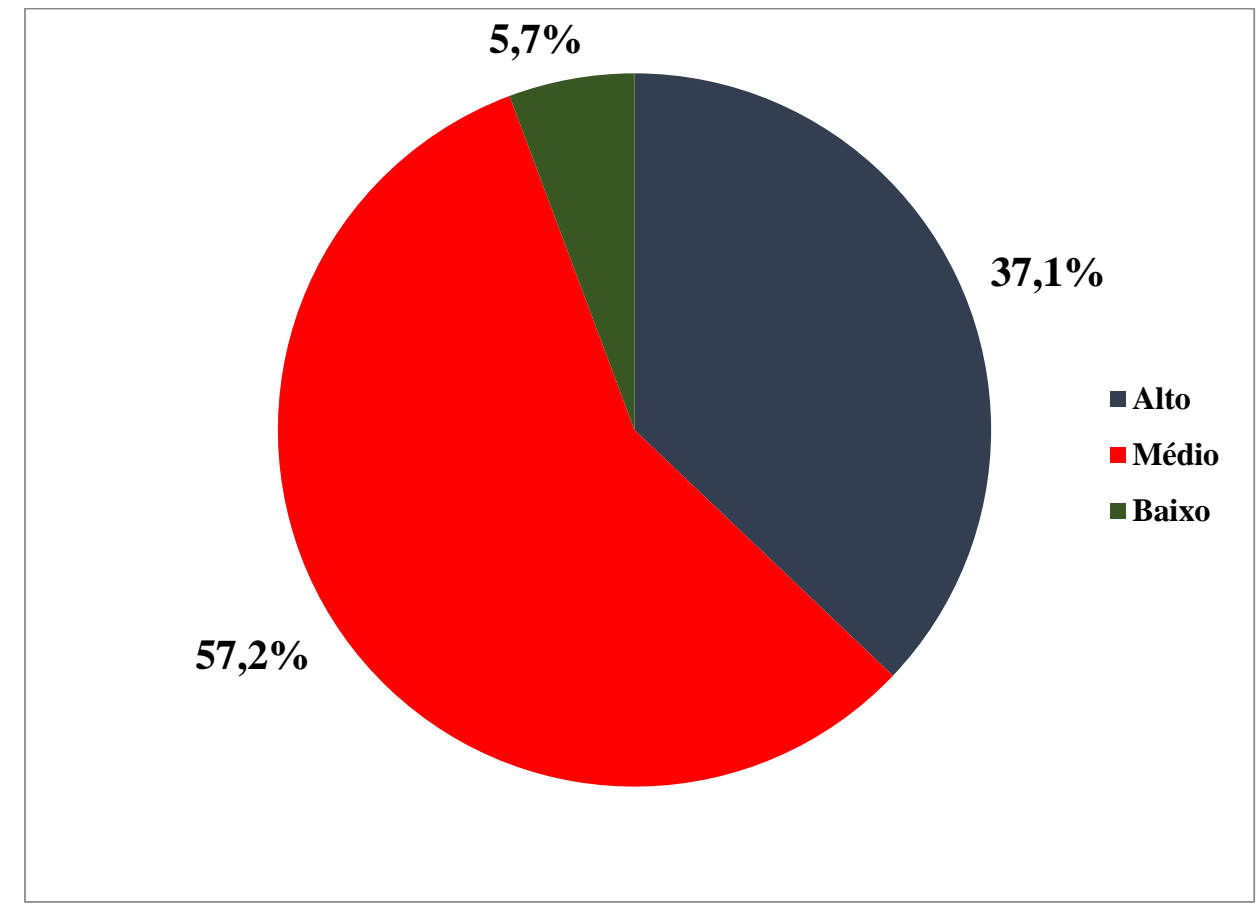

Fonte: Elaboração própria a partir de questionário aplicado no ano de 2019.

A análise dos gráficos 05 e 06 demonstra que o nível de satisfação dos egressos com a situação profissional é médio, sendo que a satisfação com o aspecto financeiro alcança um patamar superior se comparado ao aspecto social da profissão. Essa questão pode se justificada em função dos egressos que atuam em instituições de ensino da rede privada.

Apesar da satisfação social e profissional, várias respostas seguiram com alguma contestação relacionada ao aspecto financeiro e a desvalorização da profissão, refutandoas, como pode ser observado nas falas a seguir:

Sim, eu sou apaixonada apesar da desvalorização da classe e dos baixos salários (P21);

Apesar de salários baixos e na maioria das instituições públicas poucos materiais, não posso nunca dizer que a profissão não me satisfaz. Acredito que tudo ainda irá melhorar... (P 26);

Sim. O que me desanima às vezes é a demanda de trabalho que é grande e não se esgota na escola, e a hora aula a R\$12,80. (P27);

Sim, o que desanima as vezes é o salário e os problemas internos presentes na instituição. Mas amoooooo o que eu faço não trocaria nunca. (P54). 
Celia Maria Fernandes Nunes, Regina Magna Bonifácio de Araújo, Nilzilene Imaculada Lucindo e Íris Madalena Feijó Braga

\section{Dialogando com os dados das pesquisas}

Ao abarcar a contribuição de 124 egressos do curso de Pedagogia, participantes da pesquisa que se formaram entre os anos de 2012 e 2019, os achados da investigação realizada possibilitaram evidenciar questões inerentes ao campo de atuação do profissional de Pedagogia.

Quanto a análise do perfil, fica evidenciado que a maioria dos profissionais que se formaram neste curso são do sexo feminino, o que reitera a característica dessa Licenciatura com a forte presença das mulheres, conferindo também ao Magistério o título de profissão tipicamente feminina. Na concepção de Louro (2004) e Almeida (1998), a docência foi demarcada como o lugar das mulheres desde o fim do século XIX, fundamentada na premissa de que a profissão de professora é uma extensão da função materna, sendo posta como uma missão e vocação inerente às mulheres.

Alguns estudos realizados no âmbito das Licenciaturas (GATTI; BARRETTO; 2009; GATTI, 2010; GATTI et al, 2019) e também da Pós-graduação com concluintes do curso de Pedagogia (VIEIRA, 2010; VARGAS, 2016) têm demonstrado que esses cursos se constituem, em sua maioria, por mulheres. Sobre a presença maciça das mulheres no curso de Pedagogia, assim se posiciona Gatti (2010):

[...] e este não é fenômeno recente. Desde a criação das primeiras Escolas Normais, no final do século XIX, as mulheres começaram a ser recrutadas para o magistério das primeiras letras. A própria escolarização de nível médio da mulher se deu pela expansão dos cursos de formação para o magistério, permeados pela representação do ofício docente como prorrogação das atividades maternas e pela naturalização da escolha feminina pela educação (GATTI, 2010, p.1362).

Em estudo mais recente, Gatti et al (2019, p. 161) ressaltam que:

Os cursos de Pedagogia também se voltam à formação de docentes para as creches, pré-escolas e anos iniciais do ensino fundamental. À semelhança do papel que desempenharam os cursos normais do século passado, os cursos de Pedagogia são uma das mais importantes, senão a principal porta de acesso ao ensino superior das mulheres mais pobres e, em proporções significativas, menos brancas, que estão acedendo a esse nível de escolaridade. No conjunto das estudantes de sexo feminino concluintes de todos os cursos de licenciatura, as alunas de Pedagogia representam mais da metade delas $(57,4 \%)$ e, entre todos os estudantes concluintes dessa área, elas são em torno de 43,3\%.

Contudo, é relevante registrar que há uma parcela significativa do sexo oposto que tem buscado se tornar pedagogo, haja vista a presença de 07 egressos que concluíram o 
curso, objeto de estudo desta investigação. Conforme destaca Braúna (2009), há um aumento na procura do curso de Pedagogia por estudantes do sexo masculino. Essa procura específica do sexo masculino pela Pedagogia, como afirma Lucindo (2015), pode estar relacionada ao desejo de ser professor que, para Gatti et al (2019) é a principal razão para se escolher a Pedagogia e demais licenciaturas.

De acordo com os dados do Censo da Educação Superior de 2019 (BRASIL, 2020a), dentre os 10 maiores cursos de graduação por modalidade (presencial e EaD) e rede de ensino, o curso de Pedagogia ofertado pela rede federal, na modalidade presencial, ocupa o segundo lugar em número de matrículas e passa a ocupar o primeiro lugar quando se trata de oferta na modalidade EaD.

Em relação a cor/raça dos estudantes, em ambas as pesquisas fica evidenciado que o curso atendeu a mais de $70 \%$ de discentes que se declararam pardos e brancos. Em referência a esses achados é oportuno trazer para o debate a consideração exposta pelo antropólogo Kabengele Munanga (1999 e 2001), para quem a cor parda é uma categoria racial intermediária entre o branco e o preto, que além de mitigar as desigualdades raciais entre brancos e negros, dificulta a criação de uma identidade negra no país, fortalece o processo de embranquecimento e negação da negritude.

O percentual de egressos que se declararam negros se manteve na faixa dos $22 \%$ e pode ser justificado pela política de cotas adotada pela instituição. Na percepção de Vargas (2016, p.194-195),

as licenciaturas, pouco concorridas e de acesso mais fácil em comparação a cursos que proporcionam remunerações médias mais elevadas, têm atraído uma clientela que de outro modo teria poucas chances de ingressar no ensino superior, apresentando assim maior presença de pardos e pretos em comparação a cursos como Medicina.

No tocante à faixa etária, observou-se que mais de $70 \%$ dos egressos possuem idade entre 20 e 30 anos. Embora tenhamos um número menor que extrapola essa idade, trata-se de uma população que, em sua maioria, se forma bem jovem. Em seus estudos, ao apurar a faixa etária dos estudantes de Pedagogia a partir de dados do Exame Nacional de Desempenho dos Estudantes (ENADE) de 2005 e 2014, Gatti et al (2019) constataram que no ano de 2005 a maioria desses, 34,7\%, se encontrava com idade entre 18 e 24 anos, sendo que no ano de 2014, a maior percentagem, 34,4\%, se encontrava na faixa etária de 30 a 39 anos. 
Ao analisar a origem dos egressos, verificou-se que mais da metade deles são naturais da região onde a instituição encontra-se inserida, com destaque para os municípios de Ouro Preto e Mariana, e municípios vizinhos em Minas Gerais. Pode-se verificar, com isto, que a instituição cumpre um papel social importante ao atender a comunidade do seu entorno. A esse respeito, se pronunciam Santos (2015) e Pena (2017). Na concepção desses autores, a instituição adotou, após anos de muitos debates e sob forte pressão do Fórum da Igualdade Racial de Ouro Preto (FIROP), "entidade que reascendeu na cidade as lutas do povo negro, estruturou e apresentou uma ampla pauta de reivindicações à Prefeitura Municipal e endereçou à Universidade Federal de Ouro Preto solicitação da adoção de cotas raciais para ingresso nos seus cursos de graduação" (SANTOS, 2015, p. 12) e da comunidade civil, políticas afirmativas para o ingresso na instituição e tal adoção tornou o acesso aos seus cursos superiores mais democrático, sobretudo para a população de Ouro Preto e região que anteriormente a estas políticas possuíam acesso restrito à educação superior da instituição lócus desse estudo.

No que concerne à procedência da instituição em que eles concluíram a Educação Básica, os dados demonstraram que um percentual acima de $80 \%$ concluiu o Ensino Fundamental na escola pública, todavia, esse percentual é inferior quando se trata do Ensino Médio. Contudo, o índice relativo a esse nível de ensino ultrapassa os $50 \%$ dos participantes. Esse dado confirma o pertencimento dos profissionais da educação aos extratos sociais médio.

Gatti et al (2019) ao analisarem a procedência dos licenciandos segundo a dependência administrativa do Ensino Médio constataram que em 2005 esse número era de $71,1 \%$, chegando a alcançar o total de $84,8 \%$ no ano de 2014 . Acerca desses dados, as autoras afirmam que os cursos de licenciatura 'tornaram-se cursos 'populares', à medida que os seus alunos passaram a efetivamente representar as camadas majoritárias da população" (GATTI et al, 2019, p.147).

Comungando das ideias de Vargas (2016), para Setton (1999), os alunos provenientes de escolas públicas comumente são de classe desfavorecida e tem sua oportunidade de acesso ao ensino superior muito limitada. Eles ficam restritos a cursos superiores mais "populares" que

[...]oferecem baixas expectativas de profissionalização, já que levam a carreiras pouco valorizadas no mercado de trabalho. Com expectativa de baixos salários e estreitas oportunidades de empregabilidade em postos de prestígio, os estudantes desses cursos possuem uma característica em comum: são os mais habilitados a se dedicar ao magistério, carreira com baixo status social (Pedagogia, 
Biblioteconomia, Letras, Geografia, Filosofia, História e Ciências Sociais) (SETTON, 1999, p. 469).

Neste contexto, a desvalorização da profissão docente, conjuntamente com a baixa concorrência, incita os alunos oriundos de escolas públicas a participarem de processos seletivos para as Licenciaturas.

Os egressos da IES pesquisada deram sequência aos estudos e muitos ingressaram em um curso de Pós-Graduação. Observa-se que esse quantitativo foi mais expressivo dentre os participantes da primeira pesquisa. A busca pela Pós-Graduação pode estar associada ao desejo de aprofundar os estudos em alguma área específica, bem como, ascender na carreira e alcançar salários superiores ao que já recebem ou mesmo seguir a carreira acadêmica atuando como docente em instituições de ensino superior. Diversos outros motivos podem ser observados na pesquisa que Monteiro e Silva (2016) realizaram com egressos do curso de Pedagogia.

Os dados da investigação demonstraram que o mercado de trabalho é capaz de absorver a parte expressiva dos alunos que concluem o curso de Pedagogia. A partir das análises empreendidas é possível observar que um percentual acima de $74 \%$ dos egressos conseguiu uma colocação no mercado de trabalho, sendo que mais de $72 \%$ deles estão atuando na área educacional e desses, mais de 50\% atuam no setor público. Esse fato pode encontrar explicação em dois fatores, no grande número de escolas públicas que o Brasil possui e na legislação que trata da qualificação dos profissionais da educação.

Segundo dados do Censo da Educação Básica (BRASIL, 2020b), no ano de 2019, o Brasil possuía 180.610 escolas de Educação Básica, sendo que desse total, 2/3 estão sob a competência dos municípios cuja responsabilidade incide sobre a manutenção da Educação Infantil, garantindo, com prioridade, os anos iniciais do Ensino Fundamental. Não obstante, em consonância com as Diretrizes estabelecidas para o curso de Pedagogia, o pedagogo é o profissional que está apto a atuar na Educação Infantil e nos anos iniciais do Ensino Fundamental. O grande número de escolas existentes no Brasil favorece a inserção dos profissionais formados pelo curso de Pedagogia.

O segundo fator é alusivo à formação específica para atuar na área educacional que encontra respaldo nas Diretrizes do curso de Pedagogia já referenciadas e nos artigo 62 e 64 da Lei de Diretrizes e Bases da Educação Nacional n 9.394/96 (BRASIL, 1996), os quais tratam da formação dos profissionais da educação que atuarão nas escolas e nos sistema de ensino, exercendo atividades relacionadas à docência na Educação Infantil e nos anos inicias do Ensino Fundamente, além, da gestão dessas instituições. 
Art. 62. A formação de docentes para atuar na educação básica far-seá em nível superior, em curso de licenciatura plena, admitida, como formação mínima para o exercício do magistério na educação infantil e nos cinco primeiros anos do ensino fundamental, a oferecida em nível médio, na modalidade normal.

Art. 64. A formação de profissionais de educação para administração, planejamento, inspeção, supervisão e orientação educacional para a educação básica, será feita em cursos de graduação em pedagogia ou em nível de pós-graduação, a critério da instituição de ensino, garantida, nesta formação, a base comum nacional (BRASIL, 1996).

Por outro lado, esses dados também revelam que o campo majoritário de atuação do profissional de Pedagogia continua sendo as escolas e os sistemas de ensino. Ao estabelecer uma comparação entre as duas investigações, verifica-se que o número de egressos atuantes na área educacional na primeira pesquisa é de 72,9\%, ao passo que na segunda pesquisa, esse percentual é maior, alcançando o patamar de 87,5\%. Esse achado é semelhante ao encontrado por Vargas (2016) e, ainda, por Vieira (2010, p.121) que, em suas considerações, destacou que "a maioria dos egressos trabalha com educação infantil e anos iniciais do ensino fundamental". Pode-se concluir que a ênfase do curso continua residindo na docência e na formação do pedagogo para atuar em espaços escolares, reduzindo o curso a um curso de formação docente e o pedagogo a docente, além de desconsiderar a especificidade da formação pedagógica. Ao mesmo tempo, negam a Pedagogia como ciência da educação, em sua legitimidade ao direcionar toda e qualquer ação educativa, bem como apontam Libâneo e Pimenta (2011) ao ressaltarem a descaracterização do campo epistemológico da Pedagogia, o esvaziamento da teoria pedagógica; a segregação do processo de formação de professores da Educação Infantil e anos iniciais do Ensino Fundamental das demais licenciaturas; e a eliminação do processo de formação do especialista pedagogo.

Acerca da forma de obtenção do emprego, várias foram as formas de acessar o campo de trabalho, contudo, destacou-se a seleção por currículo e o ingresso via concurso público. O ingresso via concurso público pode ter estreita relação com o número de escolas, como já foi abordado anteriormente, mas que vem ocorrendo com menor frequência nos últimos anos. Já o ingresso por meio da seleção do currículo evidencia que as experiências vivenciadas durante o processo formativo e que são registradas no currículo, a exemplo dos estágios obrigatórios e não obrigatórios, dos programas institucionais, dos projetos de pesquisa e extensão, dos eventos e outras atividades extracurriculares de cunho científico, cultural e artístico podem favorecer a inserção no mercado de trabalho. 
Quanto a época de ingresso no mercado de trabalho, os dados mostraram que mais de $60 \%$ dos egressos acessaram o campo enquanto ainda cursavam Pedagogia e mais de $40 \%$ se inseriu imediatamente após a conclusão, o que reitera a capacidade do mercado em absolver os recém formados, o que já foi descrito anteriormente.

Verificou-se que os egressos apresentam um nível de satisfação médio com relação a situação profissional no aspecto social e financeiro. No entendimento de Pedro e Peixoto (2006), fatores como o salário do professor: atitude dos pais e da sociedade face aos professores; comportamento/disciplina dos alunos na sala; segurança/estabilidade no trabalho; processos para progressão na carreira, incidem sobre a insatisfação profissional. Em relação às condições sociais e financeiras da profissão, Gatti et al (2009) salientam que

[...] os estudantes atribuem às condições financeiras e sociais da profissão docente a recusa em ser professor. Entre as principais ideias discutidas, é patente a concepção de que esse profissional é, em geral, mal remunerado e desprestigiado, e daí advém boa parte dos problemas enfrentados na contemporaneidade pela profissão, como a insatisfação dos que já estão inseridos no campo da docência e a rejeição daqueles que ainda estão na iminência de se inserir no mercado de trabalho. Os relatos revelam que a docência não é uma profissão fácil: há um nível de exigência de formação e envolvimento pessoal que não justifica a desvalorização a que está sujeita no momento. [...] (GATTI et al, 2009, p.51).

Especificamente, a despeito do salário, Gatti et al (2009) destacam que ele foi o segundo fator mais citado pelos estudantes ao não optarem pelo magistério. Um dado que não surpreende ao constatar os valores que são pagos aos professores e professoras nas diferentes localidades do país, bem como o que a essa questão se faz acompanhar, como as precárias condições de trabalho, a ausência de um plano de carreira e a pouca valorização da profissão.

\section{Considerações finais}

De acordo com Dourado (2007), as políticas educacionais são materializadas nas práticas sociais, no cotidiano, no dia-a-dia das instituições e redes públicas de ensino. Ao mesmo tempo, elas não possuem autonomia diante da realidade mais ampla, da qual elas são constitutivas e constituintes. Essa reflexão coloca luz na compreensão acerca dos descompassos entre o que se estabelece enquanto normativa legal, no âmbito nacional, e o que ocorre nas unidades e sistemas educativos. 
Desde a sua criação, o curso de Pedagogia, assim como as funções e atribuições do profissional pedagogo, sempre foram controversos e provocadores de debates e reflexões. Ora essas discussões faziam o caminho da crítica, ora eram reconhecidas como centrais na formação do pedagogo e vistas como adequadas e significativas na constituição do curso.

Os poucos elementos destacados nesse artigo, se revestiram de especial relevância na discussão acerca do curso de Pedagogia e permitiram pensar que o acompanhamento dos egressos é uma excelente estratégia quando se pretende avaliar o próprio curso e a formação e inserção desse profissional no mercado de trabalho. Os resultados aqui apresentados ilustram uma realidade específica, mas ainda, refletem em muito o que se observa no restante do país: a realidade da formação do pedagogo, as condições de trabalho desse profissional, e a influência econômico-política na educação e, consequentemente, na formação e na prática desse educador.

Com base nas Diretrizes Curriculares Nacionais para o curso de Pedagogia Licenciatura, que se mostram alinhadas a um contexto, que rompe com uma concepção de pedagogo enquanto cientista da educação e não constrói outra que a substitua e seja suficiente à realidade educacional brasileira, a proposta pedagógica do curso foi construída. A imposição dessa mudança gerou conflitos, desencontros e tentativas de adaptação a uma nova forma de ser professor e de ser pedagogo. E ainda existe espaço para novas reflexões e quem sabe uma (re)construção do curso e da Pedagogia enquanto ciência da educação.

O curso de Pedagogia da Universidade Federal de Ouro Preto vem sendo acompanhado e analisado desde sua fundação, em 2008. Os egressos do curso em questão, em suas falas e na participação nessa pesquisa e nas anteriores, permitiram acreditar que essa investigação contribuiu para um olhar mais crítico ao curso, bem como aprofundar as reflexões acerca do campo de trabalho desse profissional, na região investigada.

Os estudos realizados indicaram que o nível de satisfação dos egressos com a formação e com a sua prática profissional é satisfatório e que o ingresso no campo ocorreu num tempo relativamente curto. Foram profissionais, em sua maioria, absorvidos pela área da educação, área foco de sua formação, e muitos na sala de aula da Educação Infantil e dos anos iniciais do Ensino Fundamental. A partir dos estudos teóricos e dos dados da pesquisa pode-se concluir, que a mesma indica novas temáticas de estudo em relação a formação de pedagogos, tais como, as condições de trabalho do pedagogo docente e do pedagogo gestor; a formação continuada desse profissional; especificidades para atuar na Educação de Jovens e Adultos, nos espaços não escolares, dentre outros. 
Há que se pensar no sentido da Pedagogia, no sentido da docência e da formação daquele que pode assumir outras funções na escola, para além da docência. Há que se resgatar a discussão da Pedagogia enquanto ciência da educação, enquanto espaço que poderá contribuir com o pensar a aprendizagem e o ensino para as diferentes faixas etárias e de diferentes segmentos. É com essa compreensão que vamos operar, que vamos seguir na reflexão de que elas não se esgotam aqui e agora, pois na verdade elas não estão vinculadas a um início e a um fim. Esse é um processo contínuo e permanente de construção e transformação, assim como a educação é espaço aberto de mudanças, que deve instaurar a reflexão crítica acerca do curso e da implantação das Diretrizes que formam o pedagogo.

\section{Referências}

ALBUQUERQUE, Helena Machado de Paula; HAAS, Celia. Maria; ARAUJO, Regina Magno Bonifácio. Formação de professores da educação básica no Brasil - Curso de Pedagogia - Licenciatura, em instituições da Região Sudeste. Revista Acta Scientiarum. Maringá, v.35, n.1, (p.105-115), jan-jun, 2013.

ALMEIDA, Jane Soares de. Mulher e educação: a paixão pelo possível. São Paulo: Editora UNESP, 1998

BRASIL. Instituto Nacional de Estudos e Pesquisas Educacionais Anísio Teixeira (Inep). Censo da educação superior: 2019 - divulgação dos resultados. Brasília: Instituto Nacional de Estudos e Pesquisas Educacionais Anísio Teixeira, 82p, 2020a.

BRASIL. Instituto Nacional de Estudos e Pesquisas Educacionais Anísio Teixeira (Inep). Censo da Educação Básica 2019: Resumo Técnico. Brasília, 2020 b.

BRASIL. Conselho Nacional de Educação. Resolução nº 1/2006 de 15 de maio de 2006. Institui Diretrizes Curriculares Nacionais para o Curso de Graduação em Pedagogia, licenciatura. Diário Oficial da União, Brasília, 16 maio 2006, Seção 1, p. 11. Disponível em: 〈http://portal.mec.gov.br/cne/arquivos/pdf/rcp01_06.pdf〉. Acesso em: 21 dez. 2013.

BRASIL. Lei n. 9.394, de 20 de dezembro de 1996. Dispõe sobre as Diretrizes e Bases da Educação Nacional. Diário Oficial da União, Brasília, DF, 23 dez. 1996. Disponível em: <http://www2.camara.leg.br/legin/fed/lei/1996/lei-9394-20-dezembro-1996362578-publicacaooriginal-1-pl.html>. Acesso em: 06 jun. 2020.

BRASIL. Resolução CNE/CP n. 2, de 1 de julho de 2015. Brasília, 2015. Disponível em: http://www.portal.mec.gov.br/cne/arquivos/pdf/rcp01_06.pdf.Acesso em 15 de abril de 2020. BRASIL. 
BRASIL. Resolução CNE/CP n. 2, de 20 de dezembro de 2019. Brasília , 2019. Disponível em: http://portal.mec.gov.br/docman/dezembro -2019-pdf/135951-rcp00219/file Acesso em 15 de abril de 2020

BRAUUNA, Rita de Cássia de Alcântara. A construção de identidades profissionais de estudantes de Pedagogia. In: Reunião Nacional da Associação Nacional de PósGraduação e Pesquisa em Educação, XXXII, 2009, Caxambu. Disponível em: <http://32reuniao.anped.org.br/arquivos/posteres/GT08-5280--Int.pdf>. Acesso em: 06 jul. 2015.

FERREIRA, A. B. H. de. Novo Aurélio século XXI: o dicionário da língua portuguesa. 3. ed. Rio de Janeiro: Nova Fronteira, 2004.

GATTI, Bernardete Angelina. Formação de Professores no Brasil: características e problemas. Educ. Soc., Campinas, v. 31, n. 113, p. 1355-1379, out.-dez. 2010.

GATTI, Bernardete Angelina; et al. A Atratividade da Carreira Docente no Brasil. Relatório Final. São Paulo: Fundação Carlos Chagas; Fundação Vitor Civita, 2009. Disponível em: <http://www.zerohora.com.br/pdf/15141177.pdf〉. Acesso em: 03 abr. 2018.

GATTI, Bernardete Angelina. (Coord.); BARRETTO, Elba Siqueira de Sá. Professores do Brasil: impasses e desafios. Brasília: UNESCO, 2009. Disponível em: <http://unesdoc.unesco.org/images/0018/001846/184682por.pdf>. Acesso em: 07 jun. 2013.

GATTI, Bernardete Angelina; et al. Professores do Brasil: novos cenários de formação - Brasília: UNESCO, 2019. 351 p.

DOURADO, Luiz Fernandes. Políticas e gestão da educação básica no Brasil: limites e perspectivas. Educ. Soc., Campinas, vol. 28, n. 100 - Especial, (p. 921-946), out. 2007. Disponível em http://www.cedes.unicamp.br. Acesso em: 20 fev. 2021.

LIBÂNEO, José Carlos; PIMENTA, Selma Garrido. Formação de profissionais da educação: visão crítica e perspectiva de mudança. In: PIMENTA, S. G. (Org.) Pedagogia e Pedagogos: caminhos e perspectivas. 3. ed. São Paulo: Cortez, 2011.

LOURO, Guacira Lopes. Um corpo estranho: Ensaios sobre sexualidade e teoria queer. Belo Horizonte: Autêntica, 2004

LUCINDO, Nilzilene Imaculada. Quem são os pedagogos que atuam nas instituições de ensino público da SRE-OP: um estudo sobre o perfil, a formação e a trajetória desses profissionais. 2015. 158f. Dissertação (Mestrado em Educação) - Universidade Federal de Ouro Preto, 2015. Disponível em: <http://www.repositorio.ufop.br/handle/123456789/5671>. Acesso em: 18 jun. 2016.

MONTEIRO, Liamar Nunes Silveira; SILVA, Marcelo Soares Pereira da. Egressos do Curso de Pedagogia: Sentidos, significados e dimensões de suas trajetórias formativas. Cadernos da Fucamp, v.15, n.24, p.50/67 /2016. Disponível em: 
<http://www.fucamp.edu.br/editora/index.php/cadernos/article/view/917>. Acesso em: 21 fev. 2021.

MUNANGA, Kabengele. Políticas de ação afirmativa em benefício da população negra no Brasil: um ponto de vista em defesa das cotas. Sociedade e Cultura, Goiânia, v. 4, n. 2, (p. 31-43), jul.-dez. 2001.

MUNANGA, Kabengele. Rediscutindo a mestiçagem no Brasil: identidade nacional versus identidade negra. Petrópolis: Vozes, 1999.

PAUL. Jean-Jacques. Acompanhamento de egressos do ensino superior: experiência brasileira e internacional. Cad. $C R H$, Salvador, vol.28, n.74, 2015

PEDRO, Neuza; PEIXOTO, Francisco. A satisfação profissional e auto-estima dos professores. Análise Psicológica, v. 24, n. 2, (p. 247-262), 2006.

PENA, Mariza Aparecida Costa. Caminhos de estudantes participantes da Política de Ação Afirmativa: oportunidades e desafios no ensino superior. Dissertação (Mestrado em Educação) - Universidade Federal de Ouro Preto, 2017. Disponível em: https://www.repositorio.ufop.br/handle/123456789/8719.

SANTOS. Adilson Pereira dos. Os reflexos de Durban em Ouro Preto e sua repercussão na UFOP. Rio de Janeiro: FLACSO, GEA; UERJ, LPP, 2015.

SETTON, Maria da Graça Jacintho. A divisão interna do campo universitário: uma tentativa de classificação. Revista Brasileira de Estudos Pedagógicos, Brasília, v. 80, n. 196, (p. 451-471), set./dez. 1999.

VARGAS, Michely de Lima Ferreira. Formação e inserção profissional do pedagogo: o panorama histórico desta carreira e os egressos do curso de Pedagogia presencial da Faculdade de Educação da UFMG. 2016. 297 f. Tese (Doutorado em Educação) Universidade Federal de Minas Gerais, Belo Horizonte. 2016. Disponível em: <http://www.bibliotecadigital.ufmg.br/dspace/handle/1843/BUBD-AA2H3A>. Acesso em 15 fev. 2017.

VIEIRA, Josimar. de Aparecido. Qualidade da formação inicial de pedagogos: indicadores na visão de egressos. 2010. 212 f. Tese (Doutorado em Educação) - Pontifícia Universidade Católica do Rio Grande do Sul, Porto Alegre. 2010. Disponível em: < http://repositorio.pucrs.br/dspace/bitstream/10923/2803/1/000430601-

Texto\%2BCompleto-0.pdf>. Acesso em 14 abr. 2017. 
* Celia Maria Fernandes Nunes possui Doutorado em Educação pela Pontifícia Universidade Católica do Rio de Janeiro (2004). É Professora Titular do Departamento de Educação da Universidade Federal de Ouro Preto, atuando na Graduação e Pós- Graduação, e vice-líder do Grupo de Pesquisa FOPROFI (UFOP) e membro o PRODOC (UFMG).

E-mail: celia@ufop.edu.br

ORCID:http://orcid.org/0000-0002-2338-1876

** Regina Magna Bonifácio de Araújo possui Pós-doutorado pelo Instituto de Educação da Universidade de Lisboa (2014/2015) e Doutorado em Educação pela Universidade Estadual de Campinas - UNICAMP (2007). É Professora Adjunta do Departamento de Educação da Universidade Federal de Ouro Preto, docente e pesquisadora no Programa de Pós-graduação em Educação. Coordena o Grupo de Estudos e Pesquisa em Educação de Jovens, Adultos e Idosos - GEPEJAI.

E-mail: regina.araujo@ufop.edu.br

ORCID: http://orcid.org/0000-0002-1443-4876

*** Nilzilene Imaculada Lucindo é pedagoga, docente do curso de Pedagogia da Faculdade de Educação da Universidade do Estado de Minas Gerais (UEMG), atuando também no Setor Educativo do Museu de História Natural e Jardim Botânico da Universidade Federal de Minas Gerais (UFMG). Cursa o Doutorado em Educação na Universidade Federal de Ouro Preto (UFOP), integra o Grupo de Pesquisa Formação e Profissão Docente do Departamento de Educação da UFOP e o Núcleo de Estudos e Pesquisas de Psicologia da Educação e Psicopedagogia da UEMG.

E-mail: nilzilenelucindo@yahoo.com.br

ORCID: http://orcid.org/0000-0003-2766-8951

**** Íris Madalena Feijó Braga cursa Pedagogia na Universidade Federal de Ouro Preto.

E-mail: iris.braga@aluno.ufop.edu.br

ORCID: https://orcid.org/0000-0003-1225-4350 